\title{
SUPPORTING THE TRANSITION FROM SCHOOL TO ACTIVE LIFE. CASE STUDY: FEEDBACK ANALYSIS OF THE INTERNSHIPS STUDENTS OF „VASILE ALECSANDRI” UNIVERSITY OF BACAU
}

\author{
MARIA-CRINA RADU ${ }^{1 *}$, PETRONELA SAVIN ${ }^{1}$, VALENTIN NEDEFF ${ }^{1,2}$, \\ ROXANA GRIGORE ${ }^{1}$ \\ 1 "Vasile Alecsandri" University of Bacau, Calea Marasesti 157, Bacau, 600115, Romania \\ ${ }^{2}$ The Academy of Agricultural and Forestry Sciences "Gheorghe Ionescu, Sisesti, Bucharest, \\ Romania
}

\begin{abstract}
At all stages of life, education and training are essential aspects of human development and key factors for economic growth, jobs, and social cohesion. High quality and inclusive training must be a main goal of our society, especially as we live in a very challenging period, governed by the fourth industrial revolution, that transforms economies, jobs, and the society itself. Because of this, the „Vasile Alecsandri” University of Bacau is involved as a partner, with other universities, in a project with European funding, that facilitates practical training of students at economic partners, to increase the employability of graduates and obtain feedback from employers to correlate the curriculum to the labor market. The current paper aims to present a case study related to the feedback offered by the students who carried-out internships at local economic agents, within the abovementioned project.
\end{abstract}

Keywords: practical training internships, the transition from school to active life

\section{INTRODUCTION}

In September 2015, in New York, the United Nations (UN) General Assembly adopted the document „Transforming our world: the 2030 Agenda for Sustainable Development”. The 2030 Agenda responds to global challenges by addressing, in a comprehensive manner, the issue of poverty eradication and the economic, social, and environmental dimensions of sustainable development.

Romania, as a member of the United Nations (UN) and the European Union (EU), expressed its support for the 17 Sustainable Development Goals (SDGs) of the 2030 Agenda (Figure 1) and, at its meeting of 9 November 2018, the Government of Romania, by GD no. 877/2018, adopted the National Strategy for the sustainable development of Romania 2030. Through this strategy, Romania establishes its national framework for supporting the 2030 Agenda and implementing the set of 17 SDGs. The strategy supports Romania's development on three main pillars, namely economic, social, and environmental (Figure 2).

Education, training, and lifelong learning have a central role to play in building a sustainable, resilient, competitive, and unitary society for the future, as they enable people to reach their full potential. At all stages of

\footnotetext{
* Corresponding author, email: caxinte@ub.ro

(C) 2020 Alma Mater Publishing House
} 
life, education and training are essential aspects of human development and key factors for economic growth, jobs, and social cohesion. [1]. Therefore, to succeed, we must continue to invest in people. High quality and inclusive training, at all stages of life, must be a main goal, especially as we live in a period full of changes - the fourth industrial revolution or simply ,industry 4.0", which is fundamentally different from its predecessors. Mechanical and repetitive work has been taken over by machines and the new labor market now requires people to focus on ingenuity, understanding, and creating new things. In this context, education should not be seen only as a process before entering the labor market. Education must be treated as a process that prepares young generations for the challenges of the future, encouraging innovation, meritocracy, constructive critical thinking, curiosity, conduct and emancipation [2].

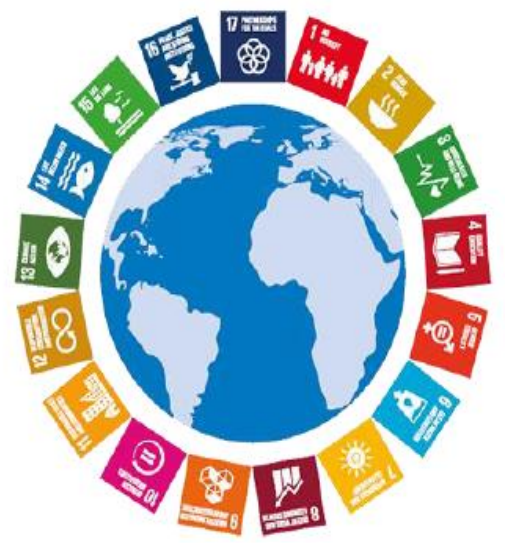

1. No poverty

2. Zero hunger

3. Good health and well-being

4. Quality education

5. Gender equality

6. Clean water and sanitation

7. Affordable and clean energy

8. Decent work and economic growth

9. Industry, innovation and infrastructure

\section{Reduced inequalities \\ 11. Sustainable cities and communities \\ 12. Responsible consumption and production \\ 13. Climate action \\ 14. Life below water \\ 15. Life on land \\ 16. Peace, justice and strong institutions \\ 17. Partnerships for the goals}

Fig. 1. The 17 Sustainable Development Goals of the 2030 Agenda [3].

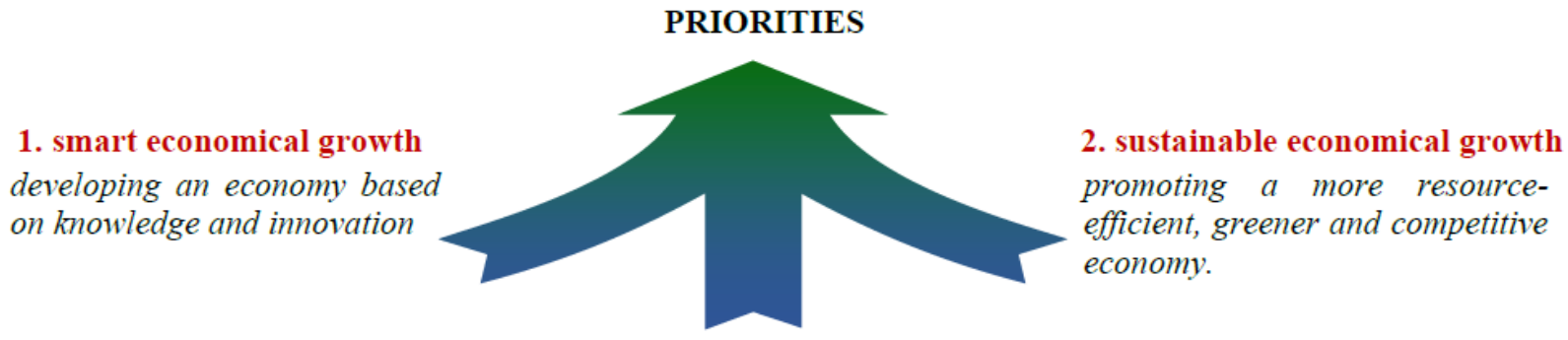

3. inclusive economical growth

promoting an economy with a high employment rate able to ensure economic, social and territorial cohesion.

Fig. 2. Thematic priorities of the 2030 Agenda.

But isolated, fragmented approaches have proven to be ineffective over time; to attend the goals, integrated strategies must be adopted, with all the interested parties involved. For this reason, to meet current and future challenges, companies must support the formation of education. They must open up, offer their knowledge to both, students and teachers so that they can be adapted to the new requirements of employers.

In Romania, employers say that graduates entering the labor market have too many theoretical skills and that they often lack the essential non-technical skills, including problem-solving, teamwork, and communication. At the same time, emigration remains at a very high level among young people, Romania being one of the EU countries with the highest number of emigrants aged between 15 and 24 [4]. Thus, it is necessary more than ever to find out a link between students and employers and analyze the feedback of both actors to identify their requirements and, accordingly, propose solutions to „fill the gaps” between them.

Through its policy and strategic direction, the „Vasile Alecsandri” University of Bacau aligns with the national strategy and sustainable development objectives, facilitating, based on partnerships with the local economic agents and beyond, the transition of students and graduates from school to active life. 
The current paper aims to present a case study related to the feedback offered by some students who have done internships at local economic agents, within a project financed from European funds.

\section{CASE STUDY - FEEDBACK OF THE INTERNSHIPS STUDENTS}

The internships were carried out within the project „Insertion on the labor market - the vector of tertiary education", co-financed by the European Social Fund through the Romanian Operational Programme (OP) "Human Capital" 2014-2020, Priority Axis 6 - "Education and skills", under the Call: POCU/320/6/21 "Measures to optimize higher education offerings in support of employability".

The project is implemented by the "Ștefan cel Mare" University of Suceava, in partnership with the University of Pitești (Partner 1), the West University of Timișoara (Partner 2) and the "Vasile Alecsandri" University of Bacau (Partner 3), during the period February 2019 - August 2021.

The internships carried out at the local economic agents were complementary activities to the courses with the applicative component, provided by the project. Each internship was defined by specific tasks, according to the students' study programmmes and was completed for two months (November 2019 - December 2019).

\subsection{Objectives of the internships at the level of the project}

The objectives of the internships consisted of [5]:

- stimulating students' motivation to integrate into society, to join a social and professional group that teach them the principles arising from independent living, autonomy, self-confidence, self-control and last but not least, to create premises for career development, including support for the transition from school to active life;

- reducing the time to adapt to the requirements of the labor market, increasing the level of competitiveness, overcoming the "handicap" of lack of experience, permanent information on the trends manifested on the labor market;

- adapting the students' skills to the demands of the labor market, facilitating the transition from school to life;

- acquisition of skills for which there is demand in the labor market, thus increasing the students' level of employability by facilitating access to employers in the local area.

\subsection{Objectives of questionnaire application}

The objectives of the current study consisted of [6]:

- identifying the perception of the "Vasile Alecsandri" University of Bacau students regarding the activity within the internships;

- surveying students' perceptions regarding the importance of internships in increasing employability;

- identifying the students' opinion regarding the conditions offered by the labor market;

- evaluating the opportunities of future graduates in direct relation to the practical training during the faculty;

- anticipating the difficulties related to the adaptation of future graduates to the labor market.

The used working tool was an 8 (eight) items questionnaire (see section 2.4).

\subsection{Target group}

The target group consisted of 42 students from two faculties: Faculty of Engineering $\left(4^{\text {th }}\right.$-year students, study programmes: Industrial Environmental Engineering and Protection - IEEP, Machine Building Technology MBT, Equipment for Industrial Processes - EIP, Industrial Energetics - IE) and Faculty of Movements, Sports and Health Sciences $\left(3^{\text {rd }}\right.$-year students, study programmes: Kinetotherapy and Special Motricity - KSM and Occupational Therapy - OT). Of these, 41 provided feedback on the satisfaction regarding the practical training carried out during the internship.

\subsection{Study's results}

The students' answers to the eight items of the questionnaire are presented in this section.

Item no. 1 (Figure 3) 
To what extent do you consider, in general, that the development of the professional practice, within the receiving institution, took place in optimal conditions?

The answers to this question prove that the students were satisfied with the development of the professional practice, appreciating the conditions in which this activity took place.

\section{Item no. 2 (Figure 4)}

To what extent do you appreciate, in general, that the educational and professional tutor-student relations were based on mutual communication, democratic, in the spirit of a constructive tutorial activity?
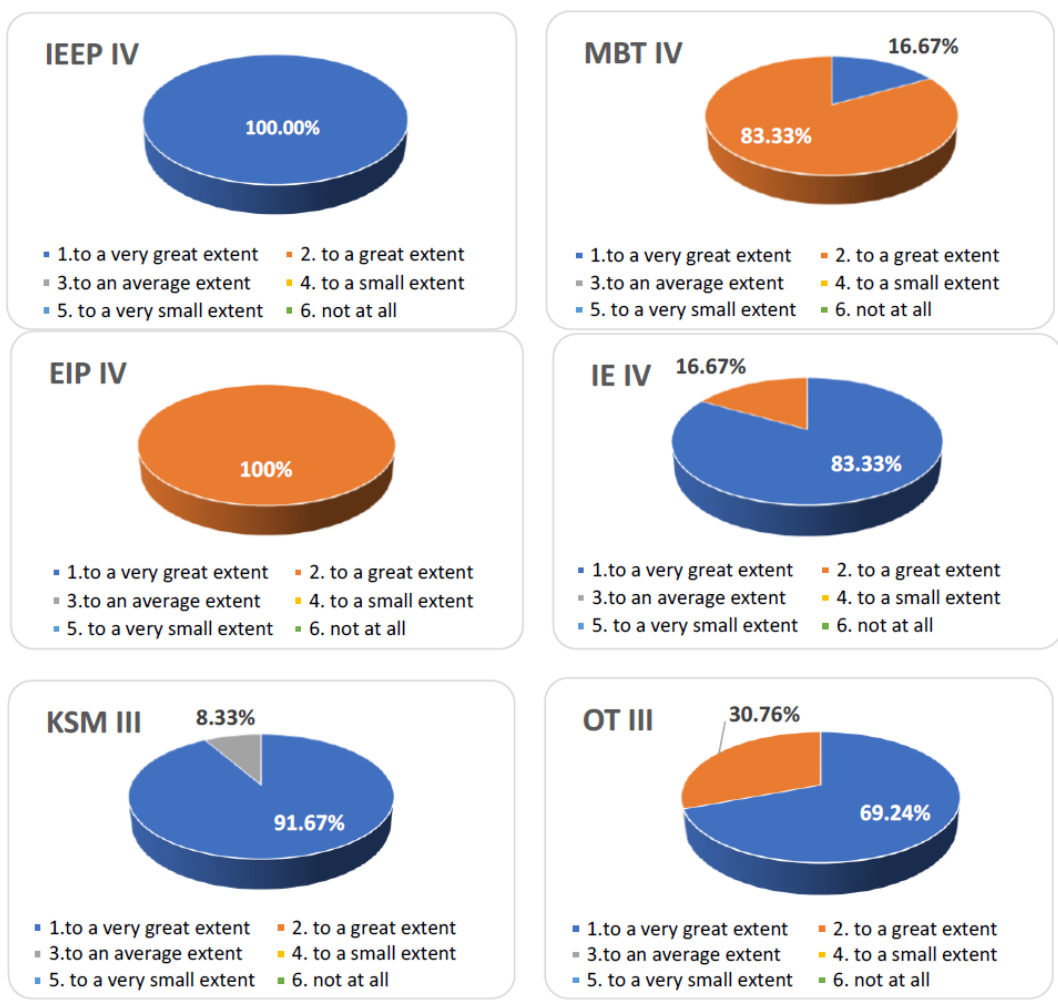

Fig. 3. Item no. 1 interpretations.

The answer to this question strengthens the opinion expressed by the answer to item 1, proving the students' awareness of the importance of the relationship with the tutor as support in increasing practical training, a basic condition for the insertion on the labor market.

\section{Item no. 3 (Figure 5)}

To what extent do you agree with the statement that the tutor gave you constructive feedback, which facilitated the timely regulation of the activities of observation, analysis, planning, and organization of practice activities?

The answers to this question show the increased interest of tutors in providing help to future employees, realizing that, currently, the labor market needs a lot of flexibility concerning human resources.

\section{Item no. 4}

Specify the strengths of the internship organization regarding the institutional capacity to organize and carry out professional internship activities.

Most of the students noticed the good organization of the institutions, high-performance equipment, professionalism, devotion, empathy, punctuality of human resources, willingness to provide information and the quality of offered information, behavior focused on student needs, correct evaluation of the knowledge acquired 
during the internship, etc. As can be seen, students have high expectations and resonate with professionalism, interest in performance, development in accordance with the world in which we live.
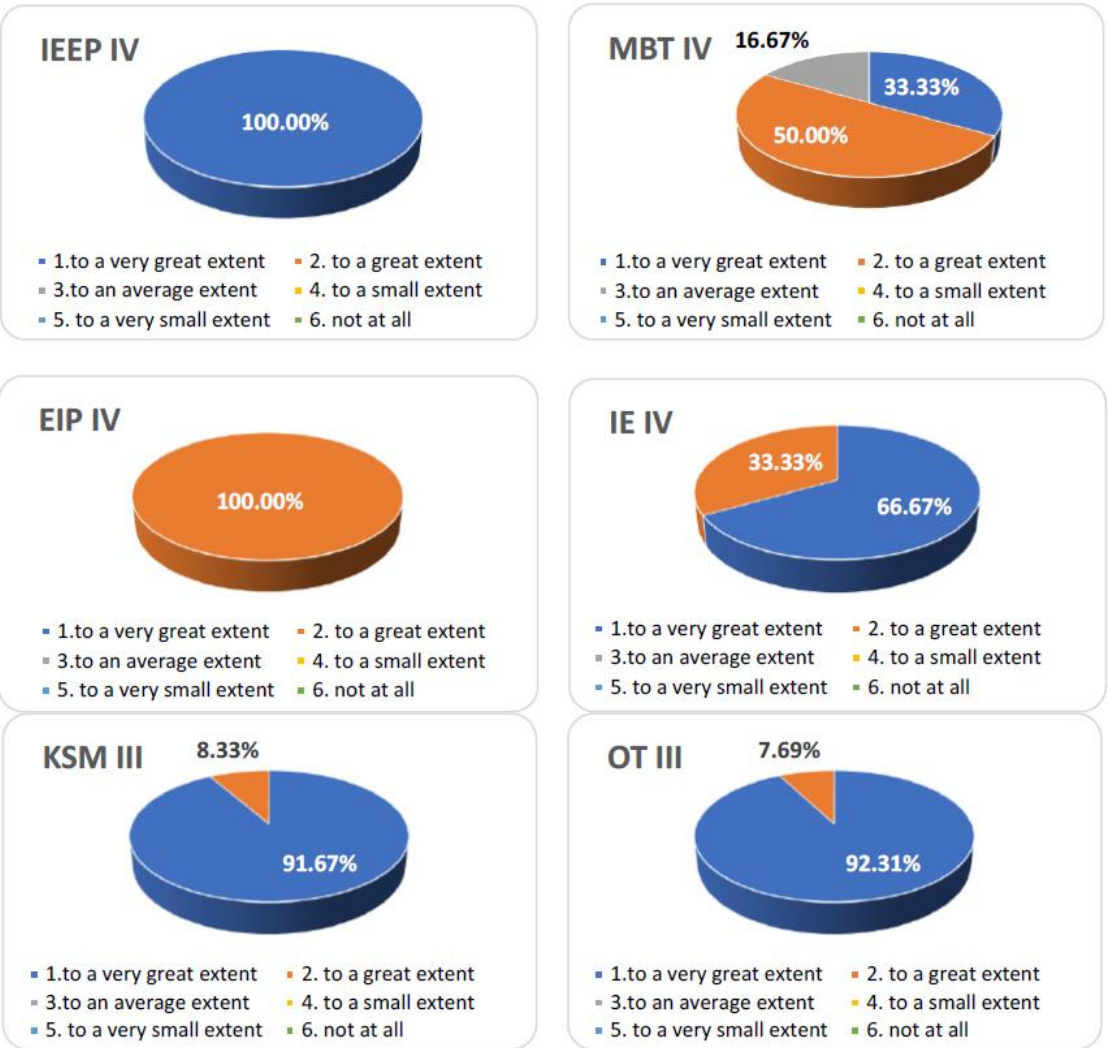

Fig. 4. Item no. 2 interpretations.

\section{Item no. 5}

Specify the weaknesses of the internship organization regarding the institutional capacity to organize and carry out professional internship activities.

Most of the students did not identify weaknesses. However, there were a few that mentioned aspects such as: the workspace of the clinic was not large enough to carry out all kinds of therapeutic activities, daily agitation due to a large number of patients, insufficient number of specialists, quite limited time allocated to discussions (OT and KSM students); a more selective ordering of tools (an MBT student), the combined electric/thermal cycle installation did not work (IE students), the internship period was too short to form an opinion (IEEP students).Analyzing the students' answers regarding the weaknesses of the internship organization, we notice the critical spirit of a generation that amends the lack of appropriate working conditions (insufficient spaces, inadequate equipment), modernization of technologies, and the insufficiency of the practical training period.

\section{Item no. 6}

Make some suggestions for improving the conditions of professional training in internship organizations.

Only a few students made suggestions for improvement, for example: focusing on group activities, better organization of patients (KSM students), the need for occupational therapy intervention, a better organization of the equipment, increasing the space to carry out activities (OT students), an advantageous program for students (MBT). Thus, regarding the suggestions to improve the conditions for professional practice, students proposed more flexibility of the program, an adaptation of working conditions to current needs, more efficient use of equipment.

\section{Item no. 7 (Figure 6)}

How useful do you consider that the internship activity, carried out within the POCU 121221 project, was for your further professional integration? 


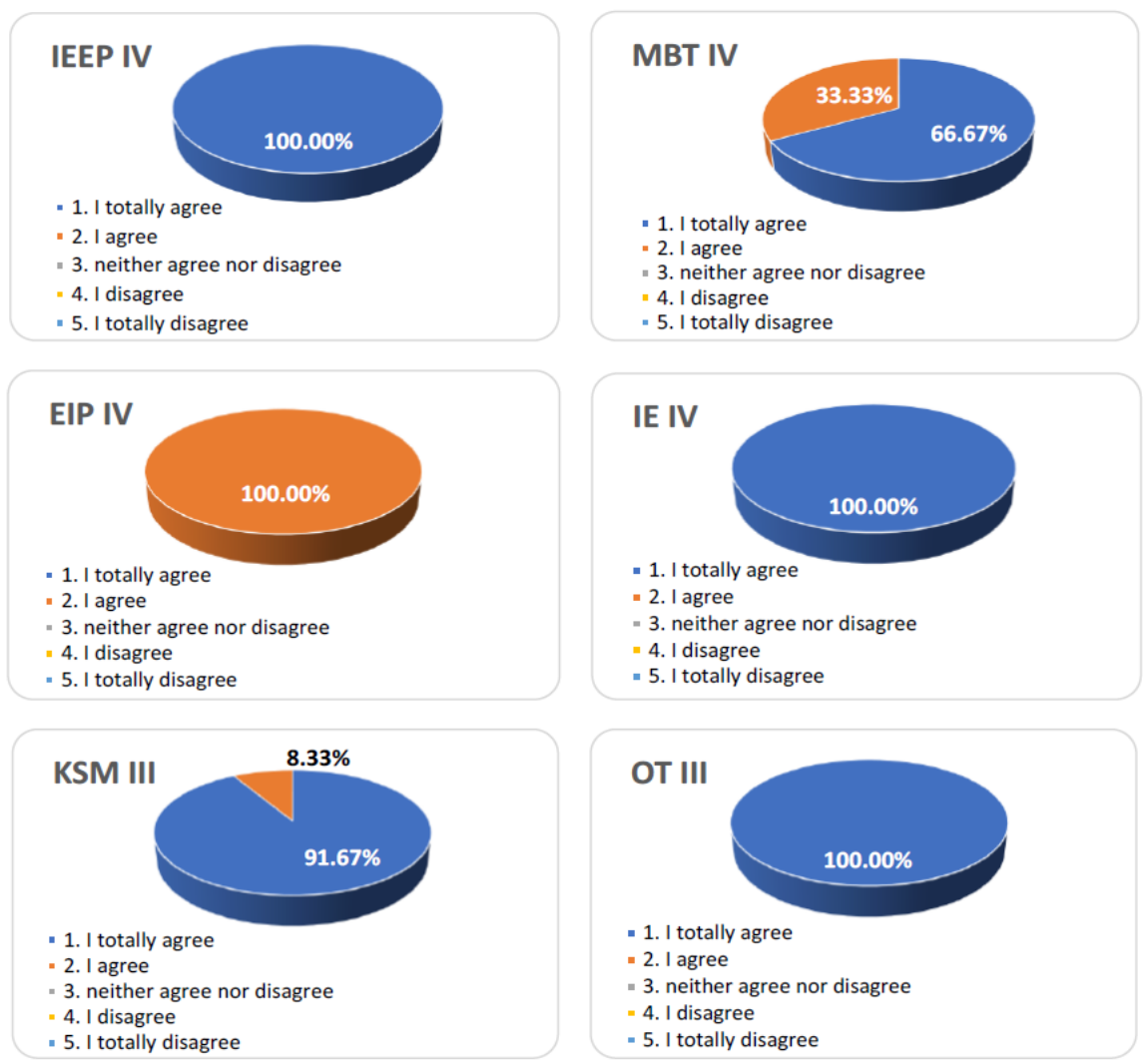

Fig. 5. Item no. 3 interpretations.
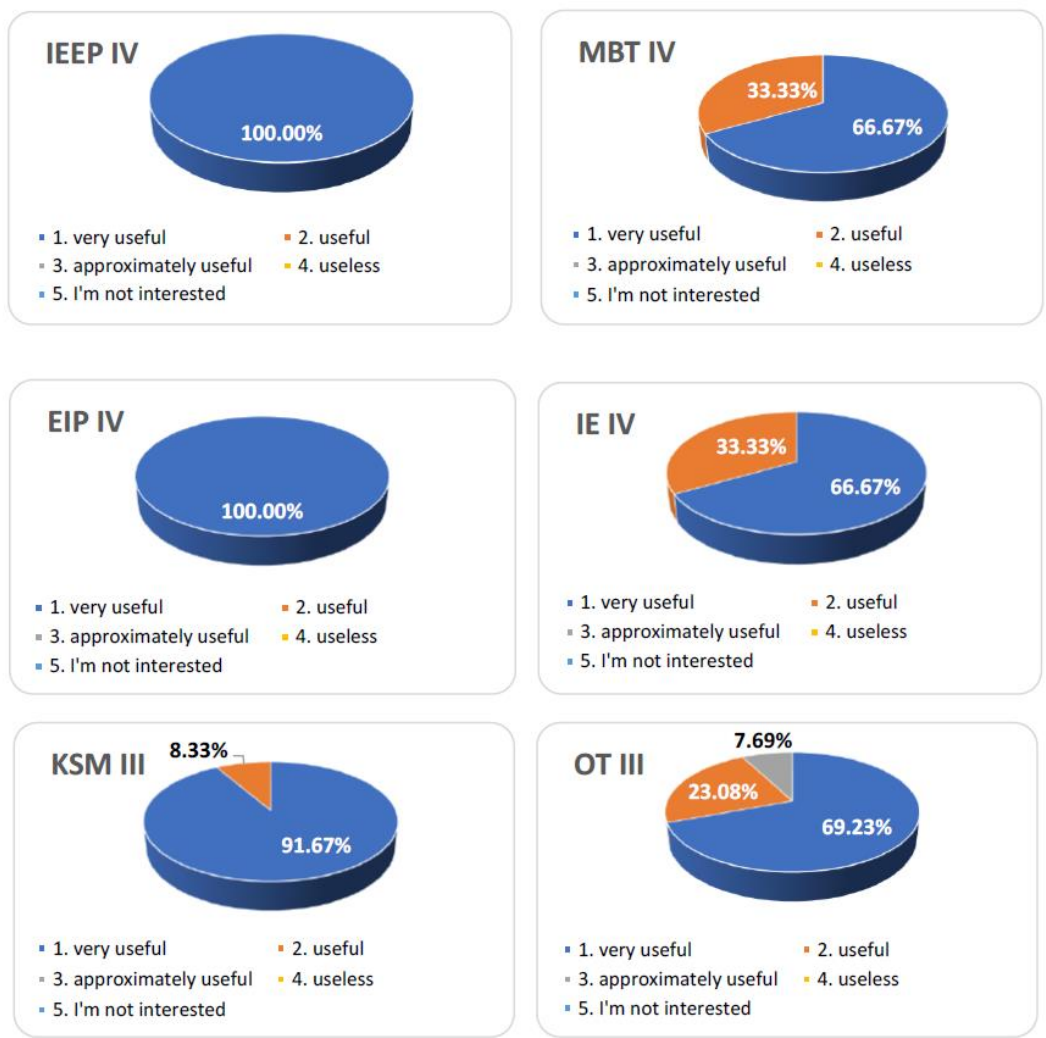

Fig. 6. Item no. 7 interpretations. 
The answers to this question, correlated with those obtained in the previous items, prove once again that students are aware of the importance of practical training during their studies, as a mandatory condition for successful integration into the labor market.

\section{Item no. 8 (Figure 7)}

Do you think that your chances of employment, in the field of the graduated specialization, increase with the completion of the internship within the POCU 121221 project?

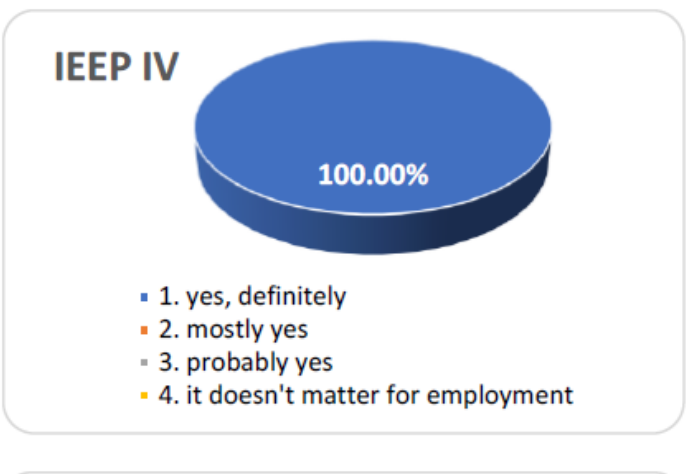

\section{EIP IV}

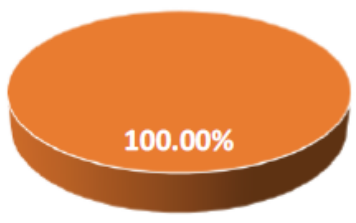

- 1. yes, definitely

- 2. mostly yes

- 3. probably yes

" 4. it doesn't matter for employment

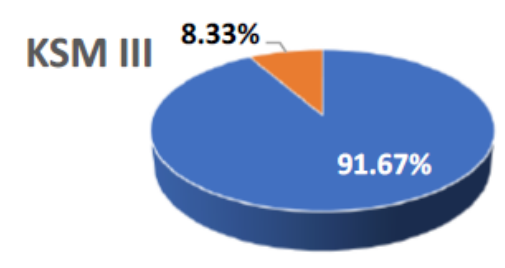

- 1 . very useful

-2. useful

-3. approximately useful $\quad=4$. useless

= 5. I'm not interested
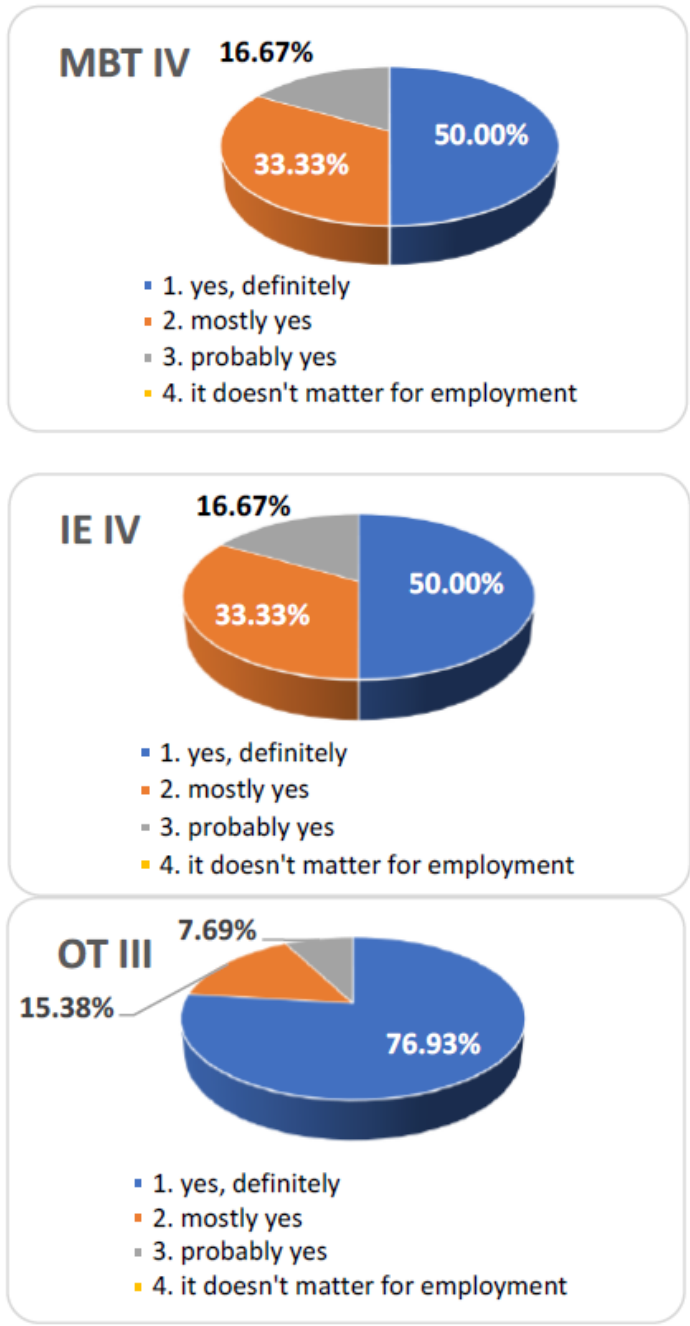

Fig. 7. Item no. 8 interpretations.

Awareness by students of the importance of internships for successful integration into the labor market is one of the important objectives of the activities carried out within the project.

\section{CONCLUSIONS}

The questionnaire addressed to the students to probe their perception regarding the practical training internship, prove a realistic and proactive attitude, the openness shown by future graduates requiring an appropriate response from the economic environment. The use of such tools to survey students' views on the activities in which they are involved is very important for strengthening the relationship between employers, students, and the university. The needs of the labor market are realized by young people who have the opportunity to manage their training according to the opportunities offered by today's society. Employers also have the opportunity to understand the needs of young people, as future employees, to realize the importance of career development for 
the current generation. The university can adapt its curriculum to the requirements of the labor market, to facilitate the transition of students to professional life. The future of university education lies in strengthening the relationship with the business environment, improving the response capacity of university education to changes in society by stimulating and supporting competitiveness and innovation in direct relation to student needs.

\section{Acknowledgments}

Authors wish to acknowledge the financial support from the European Commission, through the Romanian Operational Programme (OP) "Human Capital" 2014-2020, Priority Axis 6 - "Education and skills", under the Call: POCU/320/6/21 - "Measures to optimize higher education offerings in support of employability, the support from "Ștefan cel Mare" University of Suceava and the other partner universities, the support of partner economic agents and last but not least, the support of students in the target group who responded to our requests.

\section{REFERENCES}

[1] https://ec.europa.eu/commission/sites/beta-political/files/reflection_paper_sustainable_annexii_ro.pdf (27.05.2020)

[2] Strategia nationala pentru dezvoltare durabila a Romaniei 2030, Bucuresti, 2018.

[3] https://sustainabledevelopment.un.org/sdgs (27.05.2020).

[4] https://www.mae.ro/sites/default/files/file/anul_2019/2019_pdf/2019-european-semester-country-reportromania_ro.pdf (26.05.2020).

[5] Financing application for the project „Insertion on the labor market - the vector of tertiary education”, POCU 121221, February 2018.

[6] Radu, C., Savin, P., Nedeff, V., Analysis report of the students' perception on the conduct of the practice internship under the POCU 121221 project, April 2020. 